\title{
Macadamia Volatiles Affect the Attraction of the Moth Gymnandrosoma Aurantianum to (E)-8- Dodecenyl Acetate the Main Component of its Sex Pheromone
}

\section{Alvaro Campuzano}

ECOSUR: El Colegio de la Frontera Sur - Unidad Tapachula

\section{Edi A Malo}

ECOSUR: El Colegio de la Frontera Sur - Unidad Tapachula

Jaime Gomez

ECOSUR: El Colegio de la Frontera Sur - Unidad Tapachula

\section{Guillermo López-Guillén}

INIFAP: Instituto Nacional de Investigaciones Forestales Agricolas y Pecuarias

Leopoldo Cruz ( $\square$ lcruz@ecosur.mx )

ECOSUR: El Colegio de la Frontera Sur - Unidad Tapachula https://orcid.org/0000-0001-9569-1251

\section{Research Article}

Keywords: Sex pheromones, host plant volatiles, Gymnandrosoma aurantianum, macadamia, (E)-8dodecenyl acetate.

Posted Date: December 3rd, 2021

DOI: https://doi.org/10.21203/rs.3.rs-1129887/v1

License: (c) (i) This work is licensed under a Creative Commons Attribution 4.0 International License.

Read Full License 


\section{Abstract}

The macadamia nut borer moth Gymnandrosoma aurantianum, is the main pest of macadamia (Macadamia integrifolia) in Central America. This study investigates the effect of the host $(M$. integrifolia) on attraction of $G$. aurantianum to its sex pheromone. Y-Tube bioassays showed that females $G$. aurantianum were attracted to volatiles from $M$. integrifolia leaves and flowers, while males responded to volatiles from flowers. Both sexes had significantly different electroantennographic responses (EAG) to the extracts of volatiles from flowers, fruits and leaves and (E)-8-dodecenyl acetate (main component of the sex pheromone of $G$. aurantianum). Females $G$. aurantianum exhibited electroantennographic responses by CG-EAD to phenylacetaldehyde, (1Z)-3-methylbutanal oxime and (E)$\beta$-ocimene, while the males showed antennal activity in response to phenylacetaldehyde, (1E)-3methylbutanal oxime, (1Z)-3-methylbutanal oxime, present in the extracts of $M$. integrifolia. The EAG dose-response with ocimene (mix of isomers) showed that female antennal activity increases as the dose increases, while with males, the highest dose elicited a response that was significantly different from the control. In field tests, the mixture (ocimene/(E)-8-dodecenyl acetate) with the proportion of 10:1 was the treatment that captured the highest number of males and females. Also, we observed that the lowest number of male captures was obtained with the proportion of 1:1, compared to the traps baited with only (E)-8-dodecenyl acetate. These results suggest that the binary mixture of ocimene plus (E)-8-dodecenyl acetate in a proportion of 10:1 could be an option for monitoring this pest because we obtained captures of both sexes.

\section{Introduction}

Most phytophagous insects use plant volatiles to localize their hosts, which provide food, habitat, and oviposition sites (Bruce et al. 2005). For some lepidopterans, host volatiles can modify or stimulate production and release of sex pheromone, or they can inhibit male response to the sex pheromone produced by females (Light et al. 1993; Landolt and Phillips 1997; Fang et al. 2018). Moreover, it is known that host plant volatiles can produce a synergic effect on response to the sex pheromone in several lepidopteran species. For example, Ochieng et al. (2002) described the synergy between linalool and the main component of the sex pheromone (Z)-11-hexadecenal of the moth Helicoverpa zea (Lepidoptera: Noctuidae), based on the hypothesis that the interaction between the sex pheromone and host plant volatiles can increase male attraction. Also, a study conducted by Fang et al. (2018) indicated that the benzaldehyde, phenylacetaldehyde, and benzyl alcohol significantly increased attraction of Spodoptera litura (Lepidoptera: Noctuidae). In contrast, longifolene, $(E)$ - $\beta$-caryophyllene and $(E)-\beta$-ocimene did not have significant effect on attraction, while $( \pm)$-linalol significantly decreased attraction of the male $S$. litura when it was mixed with the sex pheromone. According to the hypothesis, host plant volatiles provide valuable information about insects because they act as habitat signals that facilitate location of mates. In some field tests, male moths have been attracted in larger numbers to traps baited with mixtures of pheromone and host plant volatiles than to traps baited with only sex pheromones (Light et al. 1993; Landolt and Phillips 1997; Deng et al. 2004). It has also been observed that the number of 
flights toward the mixtures of pheromone and host plant volatiles increased in the laboratory (Schmidt et al. 2009; Varela et al. 2011; Trona et al. 2013).

The macadamia nut borer moth Gymnandrosoma aurantianum (Lepidoptera: Tortricidae), synonymously known also as Ecdytolopha torticornis (Lepidoptera: Tortricidae) (López-Guillén et al. 2021), is the principal pest of macadamia (Macadamia integrifolia Maiden and Betche; Proteaceae) in Central America (Masís and Soto-Manitiu, 1992; López-Guillén et al. 2021). The components of the sex pheromone of this moth species have been reported as: dodecyl acetate (12: Ac), (E)-8-dodecenyl acetate (E8-12: Ac), (E)-8dodecen-1-ol (E8-12: OH) and (Z)-8-dodecenyl acetate (Z8-12: AC) (Chamberlain et al. 2003). In laboratory and field tests, the main component (E8-12: Ac) showed to be attractive to $G$. aurantianum males (Chamberlain et al. 2003). Recently, Navas-Franco (2019) also showed that this compounds attracts males of $G$. aurantianum. However, it is not known whether there is a synergic effect of host plant volatiles (M. integrifolia) with the main component of $G$. aurantianum sex pheromone (E8-12: Ac). For this reason, we studied the behavioral and electrophysiological response of $G$. aurantianum males and females to volatiles from $M$. integrifolia leaves, fruits, and flowers. The compounds that elicited antennal response were then identified by gas chromatography-mass spectrometry. Finally, field tests were done to determine whether one of the identified compounds synergize the response of $G$. aurantianum males to (E)-8-dodecenyl acetate the main component of the sex pheromone of $G$. aurantianum.

\section{Methods And Materials}

Insects. We collected G. aurantianum larvae on the Buena Vista Farm, located in the Republic of Guatemala ( $14^{\circ} 57^{\prime} 51^{\prime \prime} \mathrm{N}$ and $\left.91^{\circ} 59^{\prime} 49 \mathrm{~W}\right)$ and kept them in controlled conditions $\left(23 \pm 2^{\circ} \mathrm{C}, 75 \pm 5 \%\right.$ relative humidity and a photoperiod of $12: 12 \mathrm{hr}(\mathrm{L}: \mathrm{D})$ until the adult stage. The larvae were fed artificial diet (García and Parra, 1999), and after emergence, the adults were fed a $10 \%$ sucrose solution. For all the tests, we used 2-5 day-old virgin specimens.

Plant material. Plant material was collected from M. integrifolia cultivar Kau which it is considered highly susceptible to the nut borer. Two sizes of macadamia fruits were collected: small ( $2 \mathrm{~cm}$ diameter) and large $(3 \mathrm{~cm})$, to determine whether females have some preference in terms of fruit size. In addition, flowers and leaves were collected in the same site as mentioned above.

Collection of volatiles. Volatiles were collected using the method of dynamic headspace. The samples (fruits, flowers, and leaves) were placed inside of a glass aeration chamber $(30 \times 60 \mathrm{~cm})$. Volatiles were collected by airflow passage at $0.5 \mathrm{~L} / \mathrm{min}$, (previously purified by an activated carbon filter) over the plant material. Volatiles were collected in a glass column contained $200 \mathrm{mg}$ Porapak Q 50-80 (Waters Corporation, Milford, MA). Volatiles were collected for a period of $24 \mathrm{~h}$ at a temperature of $26 \pm 2^{\circ} \mathrm{C}, \mathrm{RH}$ $70 \pm 5 \%$, and a photoperiod of $12: 12 \mathrm{hr}(\mathrm{L}: \mathrm{D})$. Later, the volatiles were eluted from the column with $400 \mu \mathrm{L}$ dichloromethane which were concentrated to $100 \mu \mathrm{L}$ under a nitrogen flow and stored in a $1 \mathrm{ml}$ glass vial at $-20^{\circ} \mathrm{C}$ until use. 
Bioassays. The response of $G$. aurantianum adults to volatiles collected from fruits, flowers and leaves were evaluated in a glass Y-tube olfactometer (trunk of the Y-tube $15.52 \mathrm{~cm}$ long and the two arms $12 \mathrm{~cm}$ long, at $45^{\circ}$, internal diameter $2.5 \mathrm{~cm}$ ). The plant volatile extracts and the dichloromethane (control) were placed at the ends of each arm $(1 \mu \mathrm{L})$, and later, humidified air filtered with activated carbon was made to pass through each of the arms, while the insect was introduced at the base of the trunk of the olfactometer. A positive response was recorded when the insect crossed the "line of election" ( $7 \mathrm{~cm}$ after passing the intersection of the olfactometer arms) and remained at the site for 10 seconds. Each bioassay had a duration of $5 \mathrm{~min}$, and those insects that did not select after $5 \mathrm{~min}$ were excluded from the analysis. A total of 30 replications were performed per treatment. The bioassays were conducted in a dark room at a temperature of $25 \pm 1^{\circ} \mathrm{C}$ between $18: 00$ and 22:00 hr. The room was illuminated by a red light at a distance of $120 \mathrm{~cm}$ (8-10 Lux). During all the tests, the sample and the control were interspersed to avoid biases in the responses. After five replications, the olfactometer was washed with water, soap and acetone and dried in an oven at $90^{\circ} \mathrm{C}$ for one hour.

Electroantennography. The antennal response of $G$. aurantianum females and males to $M$. integrifolia volatiles, to E8-12: Ac and ocimene was determined by electroantennography (EAG). The head of the insect was carefully cut, and the reference electrode was inserted into its base, using a glass capillary, which was filled with a physiological saline solution. A segment of the antenna was cut, and the distal end of the antenna was inserted at the end of the glass capillary placed inside the recording electrode. The signals generated by the antenna passed through a high impedance amplifier (NL 1200; Syntech, Hilversum, The Netherlands) and visualized in a monitor using Syntech software to process the EAG signals. A regulator of stimulus flows (CS-05; Syntech) was used to generate stimuli at intervals of 1 min. A constant current of pure humidified air $(0.7 \mathrm{l} / \mathrm{min})$ was directed over the antenna through a glass tube $10 \mathrm{~mm}$ in diameter into which the sample was placed for its analysis. A standard aliquot $(1 \mu \mathrm{l})$ of each plant extract was loaded in a piece of filter paper $(0.5 \times 3.0 \mathrm{~cm}$, Whatman, No. 1; Whatman International, Maidstone, United Kingdom) exposed to air for $30 \mathrm{~s}$ to allow the solvent to evaporate, then inserted into a glass Pasteur pipette or sample cartridge and left for $40 \mathrm{~s}$ before applying. A new cartridge was prepared for each antenna replicate. A cartridge with a piece of filter paper loaded with $1 \mu \mathrm{l}$ of dichloromethane was used as control. A current of humidified pure air $(0.7 \mathrm{l} / \mathrm{min})$ was constantly directed onto the antenna through a $10 \mathrm{~mm}$ diameter glass tube. To present a stimulus, the pipette tip containing the test compound was inserted through a side hole located at the midpoint of a glass tube through which humidified pure air flowed at $0.5 \mathrm{l} / \mathrm{min}$. A stimulus flow controller (CS-05; Syntech) was used to generate a stimulus at 1 min intervals. The duration of stimulus was $1 \mathrm{~s}$. The continuous flow of clean air through the airflow tube and over the preparation ensured that odors were removed immediately from the vicinity. The plant extract was presented in random order and the test doses for ocimene were presented sequentially from the lowest to the highest concentration $(0.01,0.1,1,10$ y $100 \mu \mathrm{g} / \mu \mathrm{l})$. Control (dichloromethane) stimuli were presented at the beginning and end of each EAG analysis. One replicate was made with one antenna. Each plant extract and ocimene were tested on 2-5 day-old 10 males and 10 females of $G$. aurantianum. 
Gas chromatography coupled to an electroantenodetector (CG-EAD). To determine the antennal active compounds in the extracts, a gas chromatograph (Shimadzu GC-2010 Plus, Tokyo, Japan) coupled with an electroantenodetector (EAD, Syntech, Hilversum, The Netherlands), equipped with a non-polar Factor Four VF-5ms capillary column $30 \mathrm{~m}$ long with $0.25 \mathrm{~mm}$ internal diameter and a flame ionization detector (FID), as well as a split/splitless injector was used. The samples were injected in splitless mode, using hydrogen as the carrier gas at a flow of $2.0 \mathrm{ml} / \mathrm{min}$. The effluent of the capillary column was divided into two parts (1:1) using a transfer line (glass capillary with no phase) that was connected to the FID and the other to the EAD. The samples were analyzed using a temperature schedule for the chromatograph oven: initial temperature $50^{\circ} \mathrm{C}$ for $2 \mathrm{~min}$, increasing $5^{\circ} \mathrm{C} / \mathrm{min}$ up to $250^{\circ} \mathrm{C}$, with an isotherm for $10 \mathrm{~min}$. The injector temperature was $200^{\circ} \mathrm{C}$ and that of the detector was $250^{\circ} \mathrm{C}$. The signals generated by the antenna and by the FID detector passed through a high incidence amplifier (NL 1200, Syntech, Hilversum, The Netherlands) and were registered with a monitor using the software Syntech version 2.6 (1993-2003) to process the GC-EAD signals. The antennae, previously cut at their base, were inserted into two glass capillaries (for the base and the end of the antennal flagellum) provided with a saline solution. A total of 10 replications of each sample (fruits, flowers and leaves) were analyzed, using an antenna from a different specimen in each replication. Compounds were considered antennally active if they showed an incidence rate of $\geq 60 \%$ in each sample analyzed.

Identification of volatiles. The compounds that were antennally active by GC-EAD were identified in a Varian Star 3400 CX gas chromatograph coupled to a Varian selective mass detector, model Saturn 4D (Palo Alto, CA, USA). The compounds were separated using a column of methyl silicone (DB5-MS) $30 \mathrm{~m}$ long by 0.25 interior diameter. The samples were injected in splitless mode. A program of $50^{\circ} \mathrm{C}$ initial temperature $(2 \mathrm{~min})$ to a final temperature of $280^{\circ} \mathrm{C}(2 \mathrm{~min})$ with increments of $15^{\circ} \mathrm{C}$ per min. Helium was used as the carrier gas. Volatiles were analyzed using Saturn GC/MS Workstation software. Compounds were identified by comparing retention times and mass spectra of the available synthetic standards. Other compounds were identified tentatively based on comparison with the spectra library of the National Institute of Standards and Technology 2.0 (NIST) and retention indexes with those reported in the literature.

Chemicals. (E)-8-dodecenyl acetate (Alfa Chemistry, NY, USA), (E)- $\beta$-ocimene (Cayman Chemicals, Michigan, USA), ocimene (mix of isomers) (Aldrich, Toluca, Mexico).

Field tests. This assay was conducted on the Buena Vista Farm, municipality of San Pablo, department of San Marcos, Guatemala. White delta-type sticky traps $(12 \times 18 \mathrm{~cm})$ were used to capture $G$. aurantianum. These traps were baited with rubber septa that contained ocimene (10 mg), (E)-8-dodecenyl acetate $(1 \mathrm{mg})$ and a mixture of the two in different proportions $(1: 1,5: 1 \mathrm{and} 10: 1 \mathrm{mg} / \mathrm{mg})$; entomological glue was placed on the bottom of the traps. The trapping design was completely random blocks; in each block baited traps were placed, and for each treatment five blocks were installed. The blocks were set out in parallel lines with a separation of $50 \mathrm{~cm}$ between blocks. The traps were placed at a height of $3 \mathrm{~m}$ above the ground with separation of $50 \mathrm{~m}$ between traps. The traps were examined every week, and the moths captured per treatment were collected and recorded. After each examination, the traps were rotated 
within the blocks, while the baits were renewed every 14 days. Sexing was performed using the taxonomic keys employed by Adamski and Brown (2001).

Statistical analysis. The data obtained in the olfactometry tests in "Y" tubes were analyzed using the Gtest with Williams' correction. The field capture data and the EAG responses were analyzed using a oneway ANOVA. Field capture data was transformed with $\log (x+0.5)$ to comply with the assumptions of normality and homoscedasticity. The comparison of means was performed using the HSD Tukey test $(\mathrm{a}=$ $0.5)$. In both analyses, the value $P<0.05$ was considered statistically significant. Data were analyzed using the program $\mathrm{R}$ (v. 4.0.5).

\section{Results}

Attraction of Gymnandrosoma aurantianum adults to $M$. integrifolia volatiles. G. aurantianum females were significantly more attracted to $M$. integrifolia leaf $\left(\chi^{2}=4.2 ; \mathrm{df}=1 ; P<0.05\right)$ and flower $\left(\chi^{2}=3.89\right.$; df $=1 ; P<0.05)$ extracts compared to the control (dichloromethane), but they were not attracted to volatile extracts from fruits (large and small) (Fig. 1). While males were attracted only to flower volatiles $\left(\chi^{2}=\right.$ 5.36; $\mathrm{df}=1 ; P<0.05)$ (Fig. 2)

Electrophysiological response (EAG) of Gymnandrosoma aurantianum to Macadamia integrifolia volatiles and sex pheromone. Female EAG responses showed significant differences $(F=13.54$; $\mathrm{df}=5$, 54; $P<0.0001)$ to plant volatile extracts and to $(E)$-8-dodecenyl acetate. Response to the leaves volatiles was significantly different from the control, but response to fruit (large and small) volatiles was not, while the responses to flowers volatiles and the main component of the sex pheromone were statistically similar to the fruits volatiles but different to control (Fig. 3). Male exhibited EAG responses to $M$. integrifolia volatiles and to $(E)$-8-dodecenyl acetate were significantly different $(F=28.53$; $\mathrm{df}=5,54 ; P<$ $0.0001)$ from the control. It was observed that the responses to flowers and fruits volatiles were similar but significantly different to control, while the leaves volatiles and (E)-8-dodecenyl acetate showed significantly higher responses that control (Fig. 4).

Response detected by gas chromatography coupled to an electroantenodetector (GC-EAD). The GC-EAD analysis of macadamia flowers volatiles showed that $G$. aurantianum females consistently exhibited antennal responses to three compounds: (1Z) -3-methylbutanal oxime (peak 1), (E)- $\beta$-ocimene (peak 2) and phenylacetaldehyde (peak 3)(Fig. 5a). (E)- $\beta$-ocimene was the only compound of the M. integrifolia leaf volatile extract that stimulated G. aurantianum female antennae (Fig. $5 b$ ). Females showed no antennal response to volatiles from fruits (small and large). Males, on the other hand, responded only to flower volatiles: (1Z)-3-methylbutanal oxime (peak1), (1E)-3-methylbutanal oxime (peak 2) and phenylacetaldehyde (peak 3) (Fig. 6). G. aurantianum females had greater response to phenylacetaldehyde $(0.44 \mathrm{mV})$, followed by $(1 Z)$-3-methybutanal oxime $(0.37 \mathrm{mV})$ in macadamia flowers $(F)$. However, for leaves volatiles $(H)$, the antennal response to $(E)$ - $\beta$-ocimene was $0.39 \mathrm{mV}$; $(E)$ - $\beta$-ocimene is found in a larger proportion in leaf extract than in flowers extract. Male response to (1Z)-3-metilbutanal oxime was the highest $(0.36 \mathrm{mV})$, followed by phenylacetaldehyde $(0.33 \mathrm{mV})$. Relative amounts of the 
volatiles that elicited moth antennal response showed that phenylacetaldehyde was the major compound $(43.70 \%)$ in volatiles from flowers, while in leaves volatiles the major compound was $(E)-\beta$-ocimene (100\%) (Table 1).

\section{Table 1}

Antennal response $(\mathrm{mV})$ of $\mathrm{G}$. aurantianum to $M$. integrifolia volatiles $\left(\mathrm{F}=\right.$ Flowers and ${ }^{\mathrm{L}}=$ Leaves)

\begin{tabular}{|lllll|}
\hline Compounds & \multicolumn{2}{l}{ Antennal response $(\mathrm{mV}) \pm \mathrm{EE}$} & \multicolumn{2}{l|}{ Relative abundance $(\%) \pm \mathrm{EE}$} \\
\cline { 2 - 5 } & Females & Males & Flowers $^{\mathrm{F}}$ & Leaves $^{\mathrm{L}}$ \\
\hline$(1 Z)$-3-methybutanal oxime & $0.37 \pm 0.01$ & $0.36 \pm 0.02$ & $19.37 \pm 1.03$ & \\
$(1 E)$-3-methybutanal oxime & & $0.28 \pm 0.02$ & $10.51 \pm 1.03$ & \\
$($ (E)- $\beta$-ocimene & $0.33 \pm 0.01^{\mathrm{F}}$ & & $9.49 \pm 0.75$ & 100 \\
& $0.39 \pm 0.01^{\mathrm{L}}$ & & & \\
\hline Phenylacetaldehyde & $0.44 \pm 0.03$ & $0.33 \pm 0.02$ & $43.70 \pm 1.88$ & \\
\hline
\end{tabular}

Evaluation of response dose by EAG. The analysis of doses-responses by EAG in $G$. aurantianum females using the mixture of ocimene (mix of isomers) at different concentrations showed significant differences $(F=261.1 ; \mathrm{df}=5,54 ; P<0.0001)$, observing an increase in antennal response as the doses increased; the highest concentration evaluated was $100 \mu \mathrm{g}$. The analysis of means showed that all the doses evaluated were significantly different from the control, obtaining a greater response at the highest dose (Fig. 7). The doses evaluated in males showed that the dose of $1 \mu \mathrm{g}$ and the highest dose $(100 \mu \mathrm{g})$ were those that elicited greater activity in the antennae of these moths $(F=13.29$; $\mathrm{df}=5,54 ; P<0.0001)$.

Field experiment. Females were captured in the traps baited with ocimene (mix of isomers). The concentration of $10 \mathrm{mg}$ of ocimene captured significantly more females ( $4.48 \pm 0.74$ moths/seek) when it was mixed with $(E)$-8-dodecenyl acetate (sex pheromone), compared with traps baited with only ocimene (2.6 \pm 0.04 moths/week) ( $F=10.18 ; \mathrm{df}=3,96 ; P<0.0001)$ (Fig. 8). In contrast, when $1 \mathrm{mg}$ ocimene was mixed with $1 \mathrm{mg}$ of $(E)$-8-dodecenyl acetate, the capture of males was less ( $2 \pm 0.30$ moths/week) than with $(E)$-8-dodecenyl acetate alone (4.84 \pm 0.74 moths/week) $(F=9.96 ; \mathrm{df}=3,96 ; P<0.0001)$. The traps baited with a proportion of $10: 1$ (10 mg ocimene/1 $\mathrm{mg}(E)$-8-dodecenyl acetate) did not show significant differences in captures (5.12 \pm 0.74 moths/week), when compared with pheromone alone (Fig. 8).

\section{Discussion}

In this study we investigated the behavioral and electrophysiological response of $G$. aurantianum males and females to volatiles from $M$. integrifolia leaves, fruits and flowers. We found that females were attracted to volatiles from leaves and flower, while males responded to flower volatiles, but neither sex responded to fruits in the bioassays. Moreover, in field tests, we found that the addition of one of the host 
plant volatiles (ocimene) to (E)-8-dodecenyl acetate (the main component of the sex pheromone) had no synergic effect in the capture of males, but females were captured in these traps. The result of the capture of $G$. aurantianum males and females suggests that it can be used to monitor and control $G$. aurantianum. However, evaluation of the synergy of the other identified compounds is required.

These results suggest that volatiles from flowers may be involved in long-distance attraction of females and males of $G$. aurantianum, since it is known that some moths are attracted by the chemical signals of the host plant (Bäckman et al. 2001). Furthermore, these compounds can stimulate females to release their sex pheromone and mate with their conspecifics (Castrovillo and Cardé, 1980; Curkovic and Brunner 2007). Males can detect these signals from the pheromone and host plant volatiles acting synergically to detect females more easily (Yang et al. 2004; Xian et al. 2009).

When we analyzed the $G$. aurantianum antennal responses to the plant volatiles by GC-EAD, we observed differences in responses between males and females. (E)-B-Ocimene was the compound that more consistently $(100 \%)$. In various studies, $\beta$-ocimene is reported as a common compound, which is released in significant quantities in the leaves and flowers of many plant species, which can perform various biological functions within plants by potentially affecting visitors and by mediating defensive responses to herbivory (Farré-Armengol 2017). The fact that males and females of $G$. aurantianum respond differently to the macadamia volatiles might be related to the their olfactory system, as it happens in some lepidopteran species, for example, Röstelien et al. (2000), found Heliothis virescens possess specific receptor neurons for $(E)$ - $\beta$-ocimene. In addition, several studies have reported the attraction of some moths using (E)- $\beta$-ocimene in behavioral tests (Rajapakse et al. 2006; Sun et al. 2012; Borrero et al. 2015). While phenylacetaldehyde has been reported as a compound that synergizes the response to the sex pheromone of males Spodoptera litura (Fang et al. 2018).

Neither female nor male $G$. aurantianum showed attraction to fruit volatiles (small and large) in the laboratory bioassays, possibly because the volatiles emitted by these fruits are found in small quantities, as in the case of Helicoverpa armiguera female moths, the majority of which were attracted to volatiles of whole plants over fruits alone and preferred to oviposit when they were stimulated with whole plants (Jallow et al. 1999). Although the mechanism of host fruit localization of this species (G. aurantianum) is still not clear because it is a nocturnal species, orientation by host volatiles seems to be the most likely mechanism for locating fruits. It is considered that this species could be using visual or physical mechanisms to locate fruits, as is the case of some lepidopteran species (Fenemore 1988; Renwick and Chew 1994). Another apparent reason that the females were not attracted to fruits in the bioassays could be that the selected fruits were not in the suitable physiological state since, according to a study by Blanco et al. (1993), ripe fruits do not favor oviposition in nut borer females (Ecdytolopha torticornis Lepidoptera: Tortricidae). For this reason, in future work, we recommend broadening fruit selection.

In field evaluation, ocimene plus $(E)$-8-dodecenyl acetate in different proportions captured males and females. However, no synergic effect was observed in the capture of males. The mixture (ocimene/(E)-8dodecenyl acetate) with the proportion of 10:1 was the treatment that captured the highest number of 
males and females. In contrast, it was found that the binary mixture in a 1:1 proportion could be inhibiting the response to $(E)$-8-dodecenyl acetate in the field tests. Thus, the effect of the dose may have influenced G. aurantianum behavior in the field tests. In this sense, Yang et al. (2004) reported that the volatile compounds from plants can synergize attraction of the codling moth Cydia pomonella to the sex pheromone $(E, E)-8,10$-dodecadien-1-ol (codlemone); the mixture of pheromone and host plant volatiles in a proportion of $1: 100$ attracted more males than the mixtures of $1: 1$ or $1: 10,000$ in wind tunnel laboratory tests.

In contrast with our results, generally, in Lepidoptera, a synergist attractiveness effect of plant volatiles to sex pheromone occurs. For example, Xiang et al. (2019) reported an increase in the response of Grapholita molesta (Lepidoptera: Tortricidae) in both laboratory and field tests when (E)- $\beta$-ocimene or $(E)$ $\beta$-farnesene were integrated with the sex pheromone of this species, improving capture efficiency when compared with the pheromone alone. Moreover, a study conducted by Fang et al. (2018) indicated that compounds, such as benzaldehyde, phenylacetaldehyde and benzylic alcohol, significantly increased attraction of Spodoptera litura. In contrast, longifolene, $(E)-\beta$-caryophyllene and $(E)$ - $\beta$-ocimene had no significant effect on attraction, while ( \pm )-linalol significantly decreased attraction of the $S$. litura male, supporting the hypothesis that host plant volatiles act as habitat signals that can facilitate the location of a mate.

In lepidopterans, there is little information on female captures when host volatiles are mixed with sex pheromone. Using the mixture of ocimene and $(E)$-8-dodecenyl acetate has the advantage of capturing both sexes, which can be useful in monitoring and controlling $G$. aurantianum.

In conclusion, in this study we found that both sexes of $G$. aurantianum responded behaviorally and electrophysiologically, to host plant volatiles. Mixing one of the host plant volatiles (ocimene) with (E)-8dodecenyl acetate did not have a synergic effect in attracting males, but the capture of females in the field is reported. The mixture (ocimene/(E)-8-dodecenyl acetate) with the proportion of 10:1 was the treatment that captured the highest number of males and females. The capture of males and females in the same trap is advantageous for monitoring and control of G. aurantianum. However, it is necessary to evaluate the synergy of the other identified compounds.

\section{Declarations}

Funding: The authors declare that no funds, grants, or other support were received during the preparation of this manuscript.

Conflicts of interest/ competing interests: none

Author Contributions: Conception and design of the project (LCL, AJC); collection of data (AJC); performed analyses (LCL, AJC, EAM); wrote manuscript (LCL, AJC, EAM, GLG)

\section{References}


1. Adamski D, Brown J (2001) Systematic revision of the Ecdytolopha group of genera (Lepidoptera: Tortricidae: Grapholitini) in the New World. Entomol Scand Suppl 58:1-86.

2. Bäckman A, Bengtsson M, Borg-Karlsson A, Liblikas I, Witzgall P (2001) Volatiles from apple (Malus domestica) eliciting antennal responses in female codling moth Cydia pomonella (L.) (Lepidoptera: Tortricidae): effect of plant injury and sampling technique. Z Naturforsch, C J Biosci 56(3-4):262-268. https://doi.org/10.1515/znc-2001-3-415

3. Blanco-Metzler H, Watt A, Cosens D (1993) Ciclo de vida y comportamiento de oviposición de Ecdytolopha torticornis (Lepidoptera: Tortricidae) barrenador de la nuez de macadamia. Manejo Integr Plagas 29:36-39.

4. Borrero F, Becher P, Birgersson G, Bengtsson, M, Witzgall P, Saveer A (2015) Flight attraction of Spodoptera littoralis (Lepidoptera, Noctuidae) to cotton headspace and synthetic volatile blends. Front Ecol Evol 3:1-56. https://doi.org/10.3389/fevo.2015.00056

5. Bruce T, Wadhams L, Woodcock C (2005) Insect host location: a volatile situation. Trends Plant Sci 10(6):269-274. https://doi.org/10.1016/j.tplants.2005.04.003

6. Castrovillo P, Cardé R (1980) Male codling moth (Laspeyresia pomonella) orientation to visual cues in the presence of pheromones and sequences of courtship behaviors. Ann Entomol Soc Am 73:100105. https://doi.org/10.1093/aesa/73.1.100

7. Chamberlain D, Beevor P, Alan C, David R (2003) (E)-8-Dodecenyl acetate: Major component of the female sex pheromone of a Macadamia nut borer, Ecdytolopha torticornis. Entomol Exp Appl 4:1-3. https://doi.org/10.1046/j.1570-7458.2003.00035.x

8. Curkovic T, Brunner J (2007) Short communication. Pheromone inhibitors for Pandemis pyrusana males (Lepidoptera: Tortricidae). Span J Agric Res 5:385-388. https://doi.org/10.5424/sjar/2007053264

9. Deng J, Wei H, Huang Y, Du J (2004) Enhancement of attraction to sex pheromones of Spodoptera exigua by volatile compounds produced by host plants. J Chem Ecol 30:2037-2045. https://doi.org/10.1023/b:joec.0000045593.62422.73

10. Fang Y, Zeng R, Lu S, Dai L, Wan X (2018) The synergistic attractiveness effect of plant volatiles to sex pheromones in a moth. $\mathrm{J}$ Asia Pac Entomol 21:380-387. https://doi.org/10.1016/j.aspen.2018.01.009

11. Fenemore P (1988) Host-plant location and selection by adult potato moth, Phthorimaea operculella (Lepidoptera: Gelechiidae): a review. J Insect Physiol 34(3):175-177.

12. Farré-Armengol G, Filella I, Llusiá J, Peñuelas J (2017) $\beta$-Ocimene, a key floral and foliar volatile involved in multiple interactions between plants and other organisms. Molecules (Basel, Switzerland) 22(7):1148. https://doi.org/10.3390/molecules22071148

13. García M, Parra J (1999) Comparação de dietas artificiais, com fontes protéicas variáveis, para criação de Ecdytolopha aurantiana (Lima) (Lepidoptera: Tortricidae). An Soc Entomol 28(2):219-232. https://doi.org/10.1590/S0301-80591999000200004 
14. Jallow M, Zalucki M, Fitt G (1999) Role of chemical cues from cotton in mediating host selection and oviposition behaviour in Helicoverpa armigera (Hübner) (Lepidoptera: Noctuidae). Aust J Entomol 38:359-366. https://doi.org/10.1046/j.1440-6055.1999.00131.x

15. Landolt P, Phillips T (1997) Host plant influences on sex pheromone behavior of phytophagous insects. Annu Rev Entomol 42:371-391. https://doi.org/10.1146/annurev.ento.42.1.371

16. Light D, Flath R, Buttery R, et al. (1993) Host-plant green-leaf volatiles synergize the synthetic sex pheromones of the corn earworm and codling moth (Lepidoptera). Chemoecology 4:145-152. https://doi.org/10.1007/BF01256549

17. López-Guillén G, Gómez Ruiz J, Brown J, Cruz-López L, Metz M, Solís M (2021) First records of lepidoptera damaging Macadamia integrifolia (Proteaceae) fruits in Guatemala. Proc Entomol Soc Wash 123(2):341-349. https://doi.org/10.4289/0013-8797.123.2.341

18. Masís C, Soto-Manitiu J (1992) Insectos asociados a Macadamia integrifolia en Costa Rica. Agron. Costarricense 16(1):137-138.

19. Ochieng S, Park K, Baker T (2002) Host plant volatiles synergize responses of sex pheromonespecific olfactory receptor neurons in male Helicoverpa zea. J Comp Physiol A 188:325-333. https://doi.org/10.1007/s00359-002-0308-8

20. Rajapakse C, Walter G, Moore C, Hull C, Cribb B (2006) Host recognition by a polyphagous lepidopteran (Helicoverpa armigera): primary host plants, host produced volatiles and neurosensory stimulation. Physiol Entomol 31(3):270-277. https://doi.org/10.1111/j.1365-3032.2006.00517.x

21. Renwick J, Chew F (1994) Oviposition behavior in Lepidoptera. Annu Rev Entomol 39(1):377-400. https://doi.org/10.1146/annurev.en.39.010194.002113

22. Röstelien T, Borg-Karlson A, Mustaparta H (2000) Selective receptor neurone responses to (E)-betaocimene, beta-myrcene, E,E-alpha-farnesene and homo-farnesene in the moth Heliothis virescens, identified by gas chromatography linked to electrophysiology. J Comp Physiol A 186(9):833-847. https://doi.org/10.1007/s003590000136

23. Schmidt D, Von M, Guerin $P$ (2009) Host plant volatiles serve to increase the response of male European grape berry moths, Eupoecilia ambiguella, to their sex pheromone. J Comp Physiol A 195:853-864. https://doi.org/10.1007/s00359-009-0464-1

24. Sun J, Huang L, Wang C (2012) Electrophysiological and behavioral responses of Helicoverpa assulta (Lepidoptera: Noctuidae) to tobacco volatiles. Arthropod Plant Interact 6:375-384. https://doi.org/10.1007/s11829-012-9190-7

25. Trona F, Anfora G, Balkenius A, Bengtsson M, Tasin M, Knight A (2013) Neural coding merges sex and habitat chemosensory signals in an insect herbivore. Proc R Soc Lond B Biol Sci 280:2-67. https://doi.org/10.1098/rspb.2013.0267

26. Varela N, Avilla J, Anton S, Gemeno C (2011) Synergism of pheromone and host plant volatile blends in the attraction of Grapholita molesta males. Entomol Exp Appl 141:114-122. https://doi.org/10.1111/j.1570-7458.2011.01171.x 
27. Xiang, H, Chen Z, Li X, Guo Y, li X, Ma R (2019) Two terpenoids activates close mating behavior and enhances trap efficiency of sex pheromone of Grapholita molesta. J Asia-Pac Entomol 22(4):11091114. https://doi.org/10.1016/j.aspen.2019.08.003

28. Yang Z, Bengtsson M, Witzgall P (2004) Host plant volatiles synergize response to sex pheromone in codling moth, Cydia pomonella. J Chem Ecol 30:619-629.

https://doi.org/10.1023/B:JOEC.0000018633.94002.af

\section{Figures}

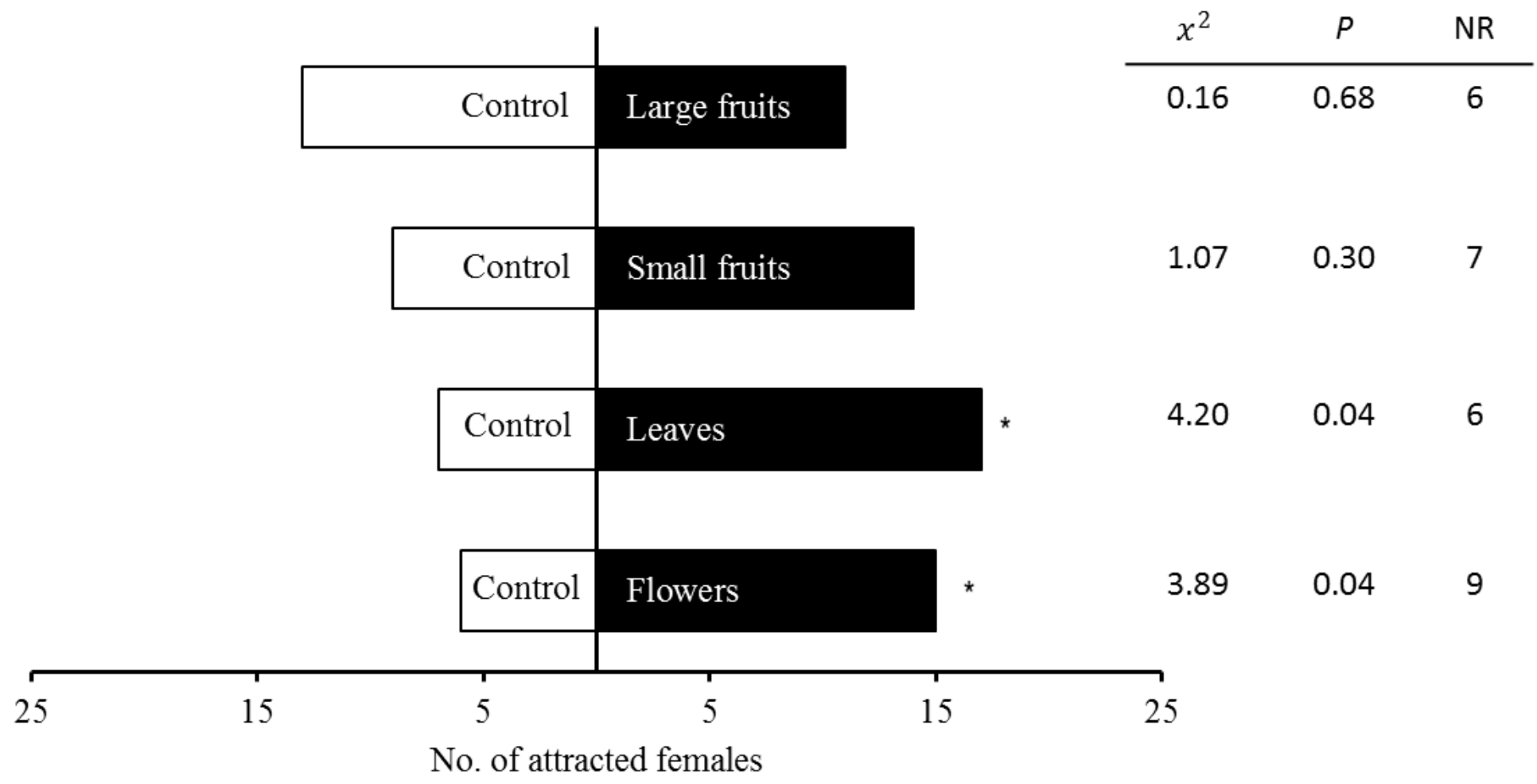

\section{Figure 1}

Attraction of Gymnandrosoma aurantianum females to Macadamia integrifolia volatiles using a Y-tube olfactometer. NR = Number of non-responding females. The asterisks indicate significant values in each comparison ( $\mathrm{P}<0.05) . \mathrm{N}=30$ 


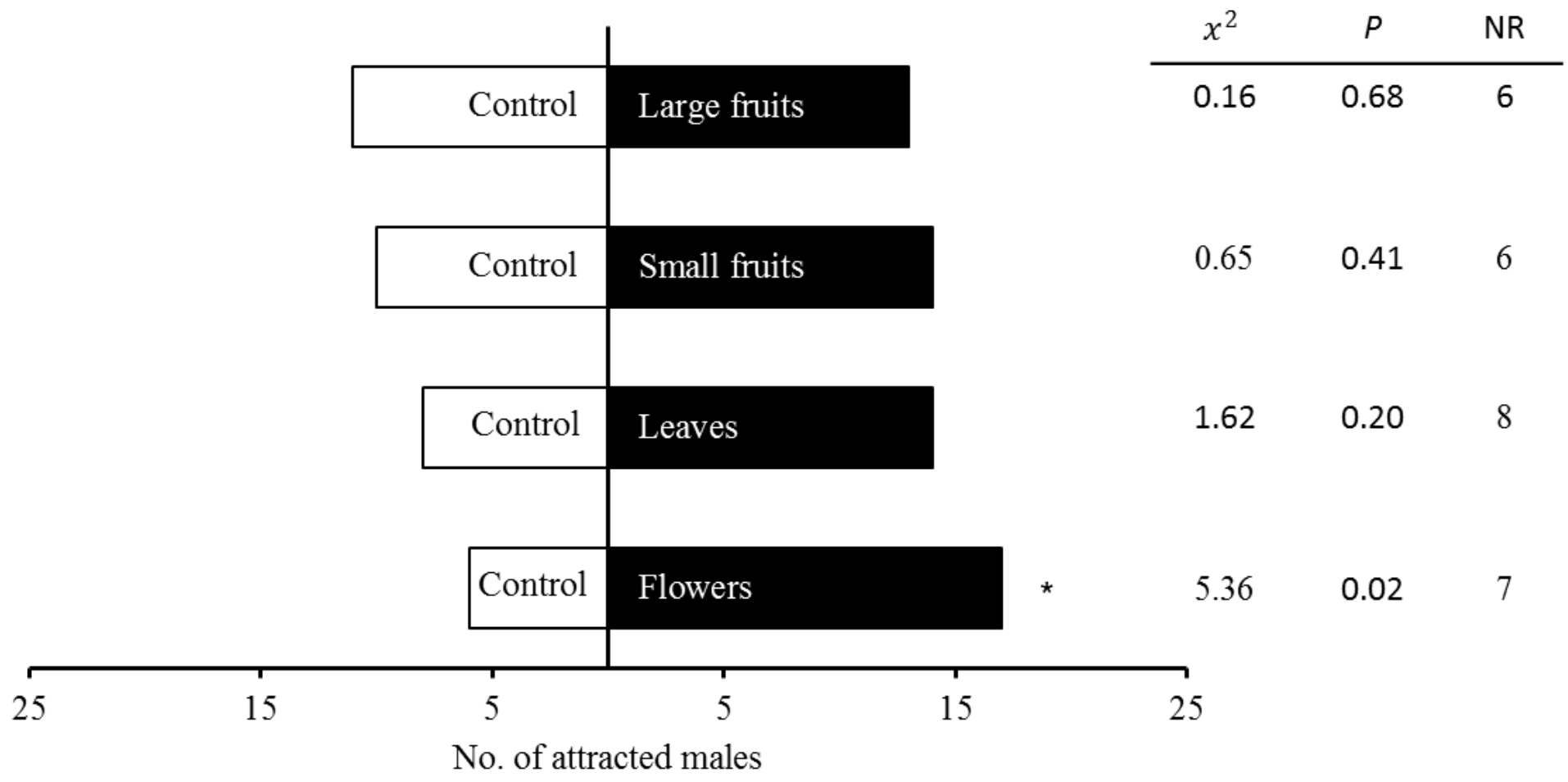

Figure 2

Attraction of Gymnandrosoma aurantianum males to Macadamia integrifolia volatiles using a Y-tube olfactometer. NR = Number of non-responding males. The asterisks indicate significant values in each comparison ( $\mathrm{P}<0.05) . \mathrm{N}=30$ 


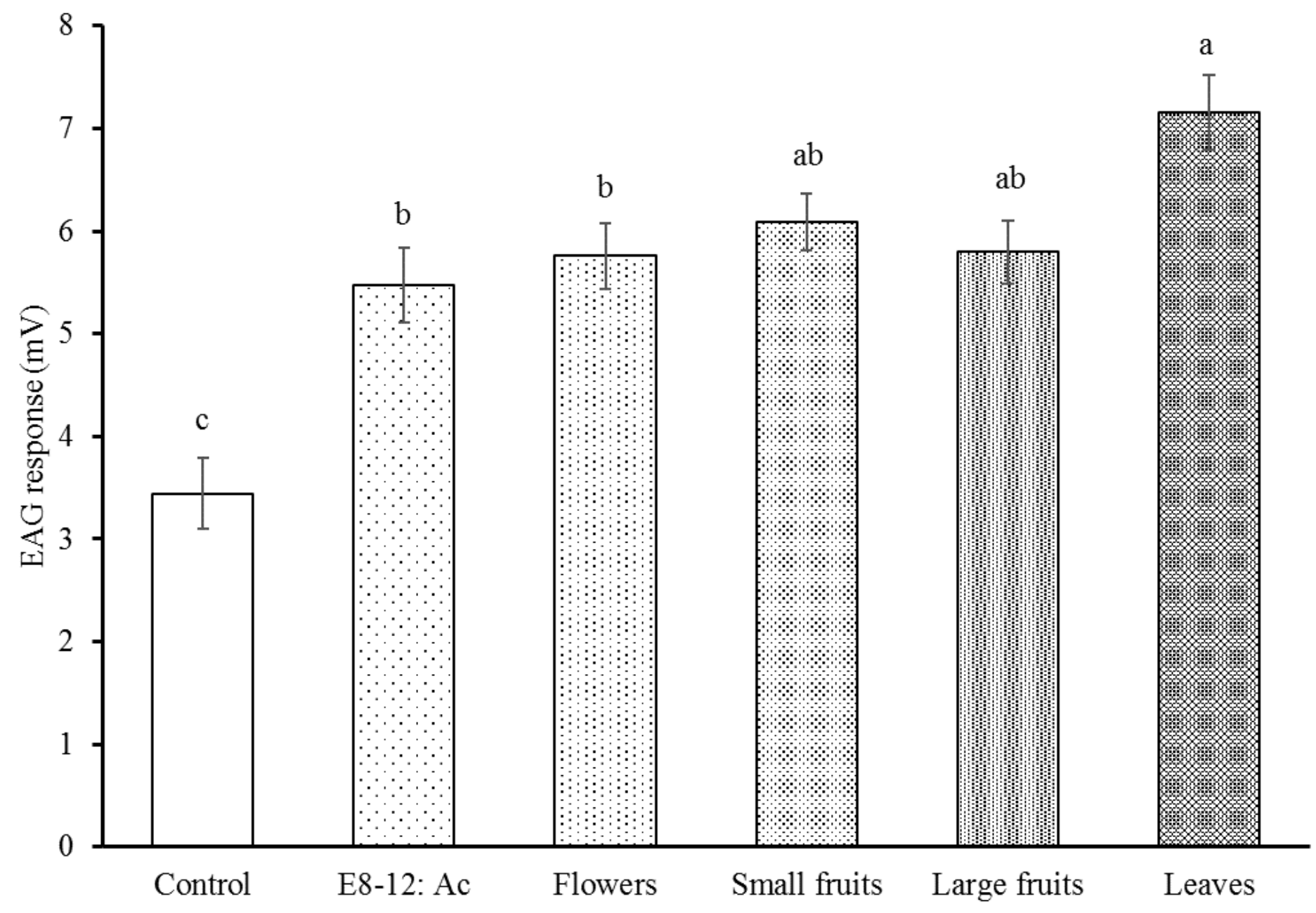

Figure 3

EAG responses (means $\pm \mathrm{SE}$ ) of Gymnandrosoma aurantianum females to Macadamia integrifolia volatiles and sex pheromone (E8-12: Ac). Significantly different means are indicated with different letters (HSD Tukey, $\mathrm{P}<0.05$ ). 


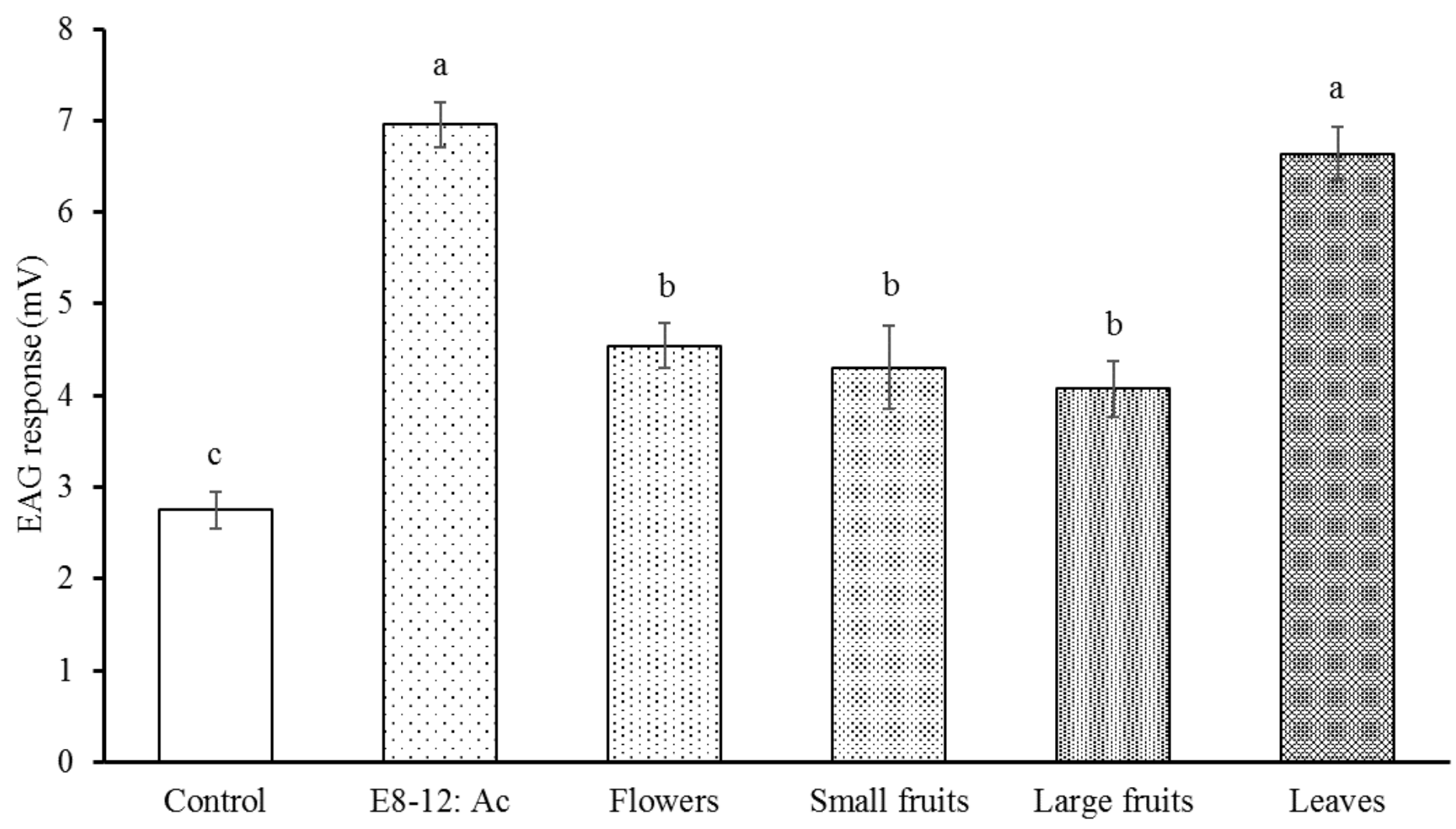

Figure 4

EAG responses (means $\pm \mathrm{SE}$ ) of Gymnandrosoma aurantianum males to Macadamia integrifolia volatiles and sex pheromone (E8-12: Ac). Significantly different means are indicated with different letters (HSD Tukey, $\mathrm{P}<0.05)$. 
FID: $10 \mathrm{mV} / \mathrm{div}$; EAD: $0.5 \mathrm{mV} / \mathrm{div}$; Horz: $40 \mathrm{~s} / \mathrm{div}$
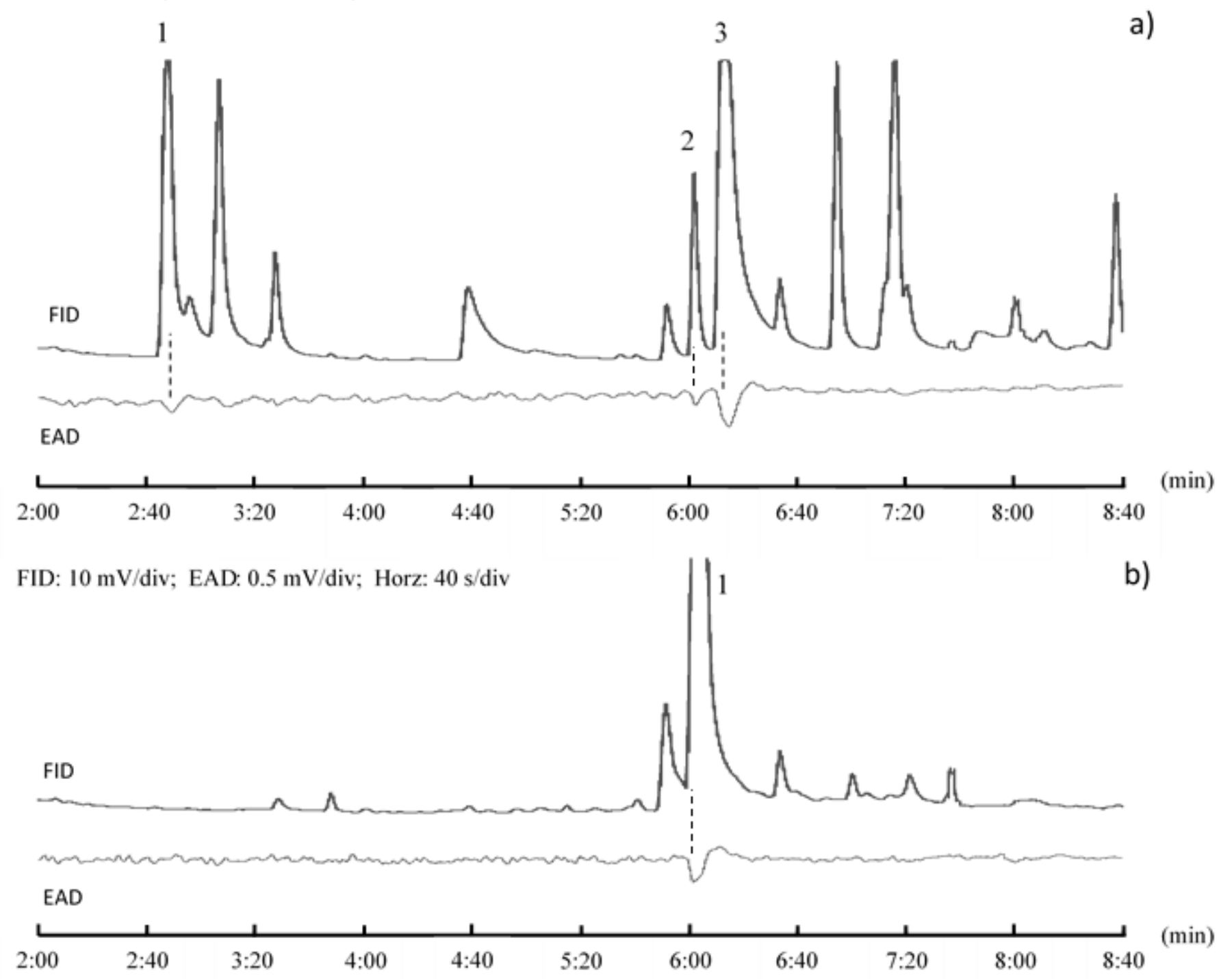

\section{Figure 5}

Simultaneous responses of Gymnandrosoma aurantianum females to Macadamia integrifolia volatiles using the flame ionization detector (FID) and electroantennographic detection (EAD). a) flower volatiles; peak 1(1Z) -3-methylbutanal oxime), peak 2 (E)-ß-ocimene), peak 3(Phenylacetaldehyde) b) leaf volatiles; peak $1((E)-\beta$-ocimene). 
FID: $10 \mathrm{mV} / \mathrm{div}$; EAD: $0.5 \mathrm{mV} / \mathrm{div}$; Horz: $40 \mathrm{~s} / \mathrm{div}$

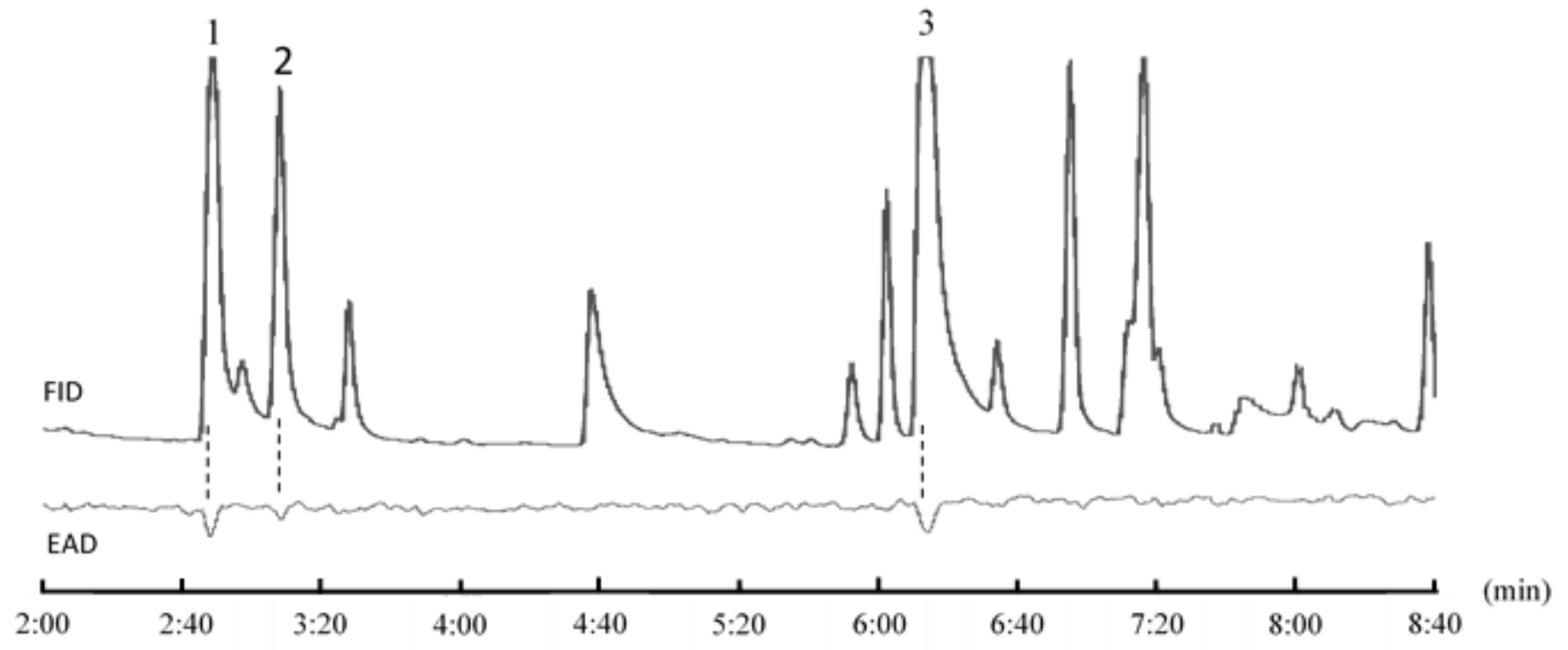

Figure 6

Simultaneous responses of Gymnandrosoma aurantianum males to Macadamia integrifolia volatiles using the flame ionization detector (FID) and electroantennographic detection (EAD). Peak 1((1Z)-3methylbutanal oxime), peak 2 ((1E)-3-methybutanal oxime) and peak 3 (Phenylacetaldehyde).

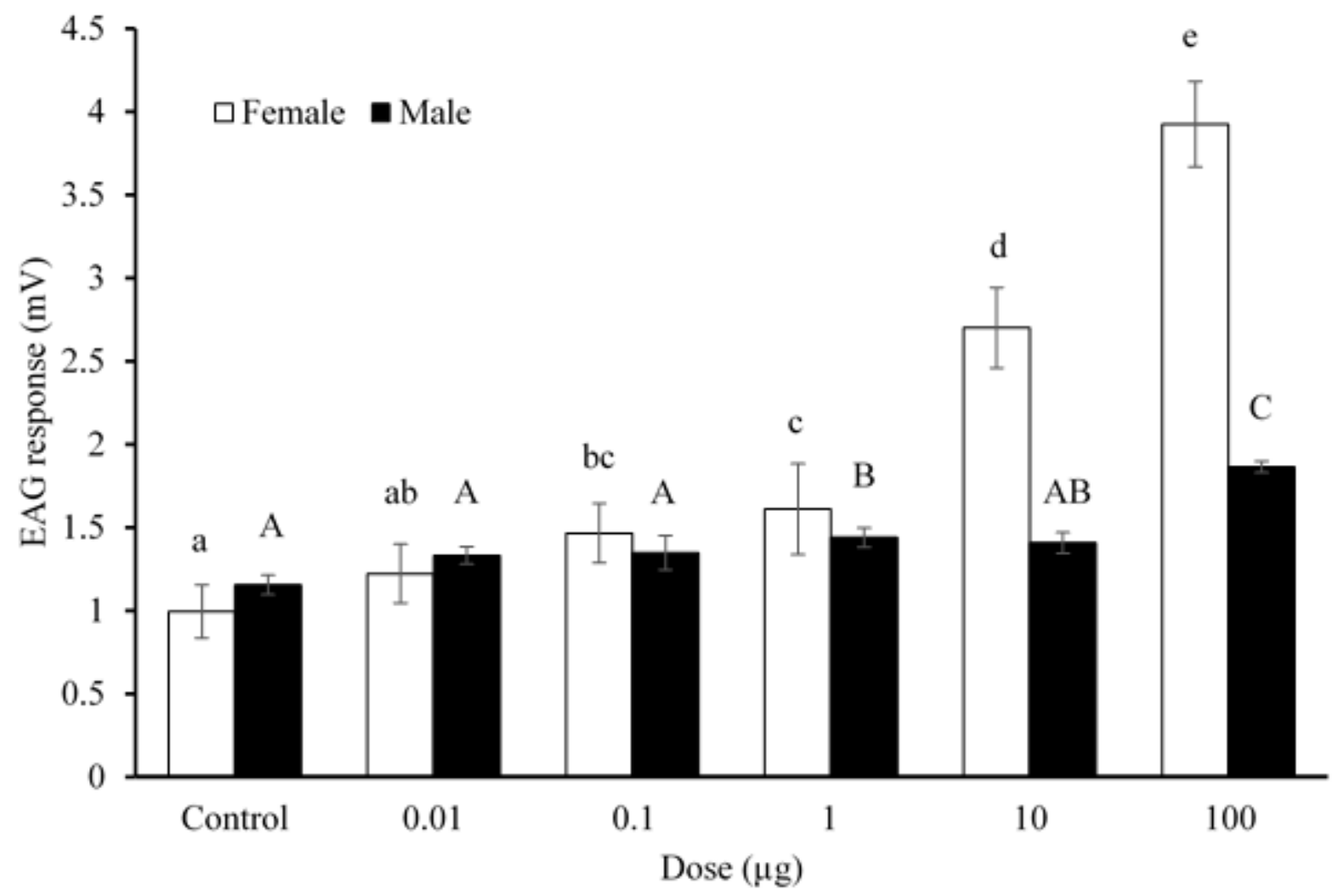

Figure 7 
EAG responses (means \pm SE) to different doses of ocimene of Gymnandrosoma aurantianum females (white bars) and males (black bars) with increasing doses of ocimene. Means followed by different letters (uppercase letters for males and lowercase for females) are significantly different (HSD Tukey, $\mathrm{P}<$ 0.05).

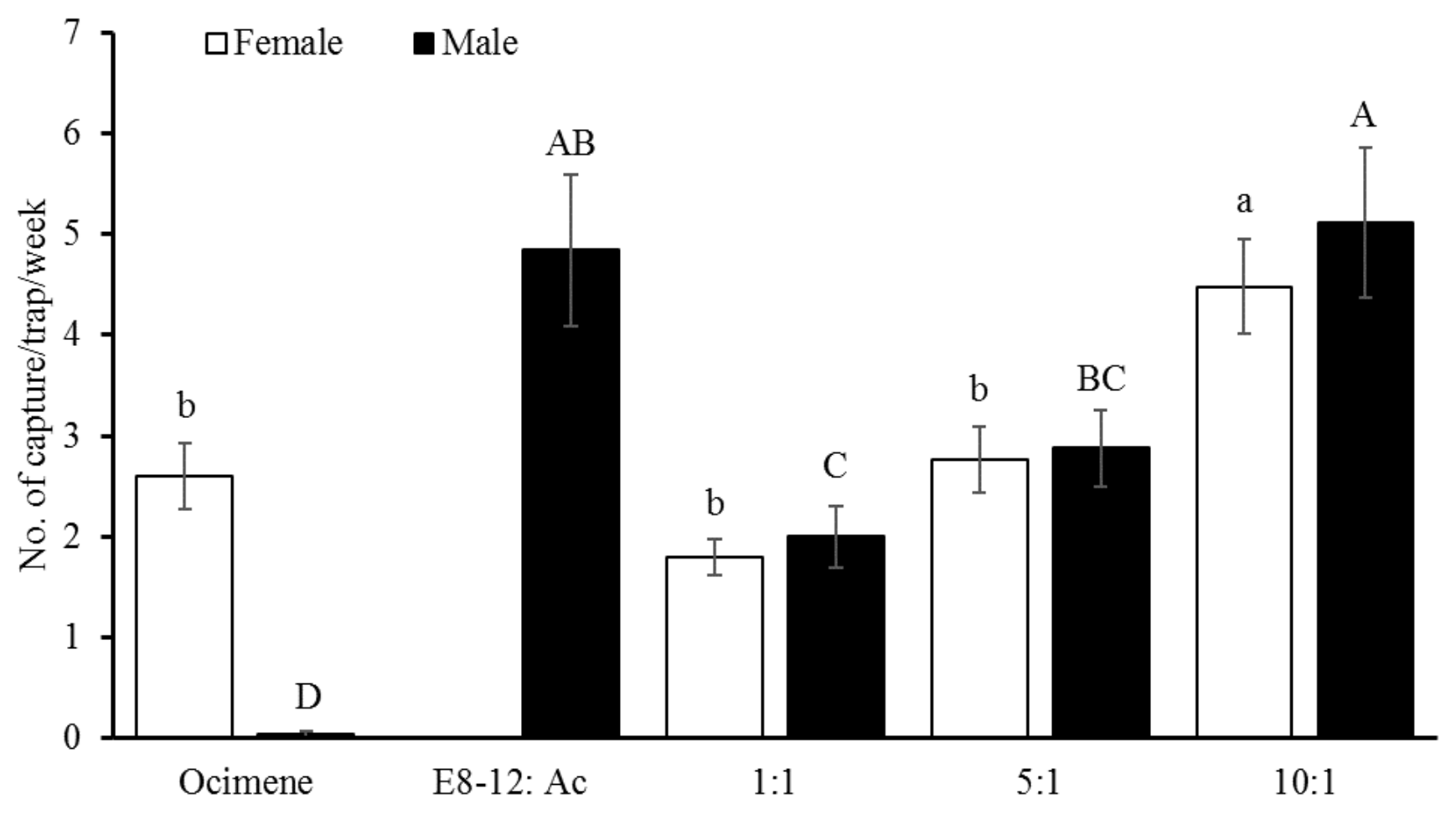

\section{Figure 8}

Capture (means \pm SE) of Gymnandrosoma aurantianum females (white bars) and males (black bars) in traps baited with ocimene $(10 \mathrm{mg})$, pheromone $(1 \mathrm{mg})$ and binary mixtures. The proportions used in the mixtures were $1 \mathrm{mg}$ ocimene/1 mg pheromone (1:1), $5 \mathrm{mg}$ ocimene/ $1 \mathrm{mg}$ pheromone (5:1), $10 \mathrm{mg}$ ocimene/1 mg pheromone (10:1). Means followed by different letters (uppercase letters for males and lowercase for females) are significantly different (HSD Tukey, $\mathrm{P}<0.05)$. 